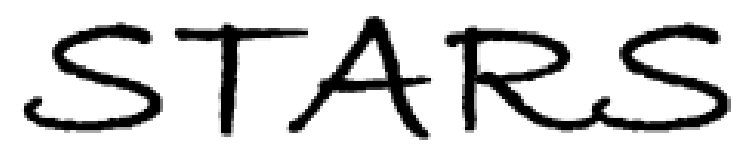

University of Central Florida

STARS

$1-1-2005$

\title{
Fluorene-based fluorescent probes with high two-photon action cross-sections for biological multiphoton imaging applications
}

\author{
Katherine J. Schafer-Hales \\ University of Central Florida \\ Kevin D. Belfield \\ University of Central Florida \\ Sheng Yao \\ University of Central Florida \\ Peter K. Frederiksen \\ University of Central Florida \\ Joel M. Hales \\ University of Central Florida \\ Find similar works at: https://stars.library.ucf.edu/facultybib2000 \\ University of Central Florida Libraries http://library.ucf.edu \\ See next page for additional authors \\ This Article; Proceedings Paper is brought to you for free and open access by the Faculty Bibliography at STARS. It \\ has been accepted for inclusion in Faculty Bibliography 2000s by an authorized administrator of STARS. For more \\ information, please contact STARS@ucf.edu.
}

\section{Recommended Citation}

Schafer-Hales, Katherine J.; Belfield, Kevin D.; Yao, Sheng; Frederiksen, Peter K.; Hales, Joel M.; and Kolattukudy, Pappachan E., "Fluorene-based fluorescent probes with high two-photon action crosssections for biological multiphoton imaging applications" (2005). Faculty Bibliography 2000s. 5637. https://stars.library.ucf.edu/facultybib2000/5637

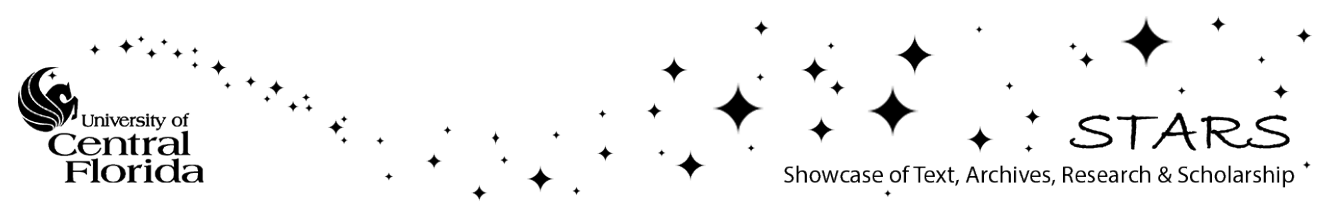




\section{Authors}

Katherine J. Schafer-Hales, Kevin D. Belfield, Sheng Yao, Peter K. Frederiksen, Joel M. Hales, and Pappachan E. Kolattukudy 


\section{Fluorene-based fluorescent probes with high two-photon action cross-sections for biological multiphoton imaging applications}

\author{
Katherine J. Schafer-Hales \\ University of Central Florida \\ Department of Chemistry and Burnett College \\ of Biomedical Sciences \\ 4000 Central Florida Boulevard \\ Orlando, Florida 32816 \\ Kevin D. Belfield \\ University of Central Florida \\ Department of Chemistry and College of Optics \\ and Photonics: Center for Research and \\ Education in Optics and Lasers and Florida \\ Photonics Center of Excellence and \\ Burnett College of Biomedical Sciences \\ 4000 Central Florida Boulevard \\ Orlando, Florida 32816
}

\section{Sheng Yao \\ University of Central Florida \\ Department of Chemistry \\ 4000 Central Florida Boulevard \\ Orlando, Florida 32816}

\section{Peter K. Frederiksen}

University of Central Florida

Department of Chemistry and College of Optics and Photonics: Center for Research and

Education in Optics and Lasers and Florida

Photonics Center of Excellence

4000 Central Florida Boulevard

Orlando, Florida 32816

\section{Joel M. Hales}

University of Central Florida

College of Optics and Photonics: Center for Research and Education in Optics and Lasers and Florida Photonics Center of Excellence

4000 Central Florida Boulevard

Orlando, Florida 32816

\section{Pappachan E. Kolattukudy}

University of Central Florida

Burnett College of Biomedical Sciences

4000 Central Florida Boulevard

Orlando, Florida 32816

\begin{abstract}
Two-photon fluorescence microscopy is a powerful tool for the study of dynamic cellular processes and live-cell imaging. Many commercially available fluorescent probes have been used in multiphoton-based imaging studies despite exhibiting relatively low two-photon absorption cross-section values in the tunability range of ultrafast Ti:sapphire lasers commonly used in multiphoton microscopy imaging. Furthermore, available fluorophores may be plagued with low fluorescence quantum yield and/or photoinstability (i.e., photobleaching) on exposure to the high peak power and photon density provided by the ultrafast laser source. To address the demand for better performing dyes, we prepare fluorophores tailored for multiphoton imaging. These fluorophores are based on the fluorene ring system, known to exhibit high fluorescence quantum yield $(>0.7)$ and high photostability. Furthermore, an amine-reactive fluorescent probe for the covalent attachment onto amine-containing biomolecules is also prepared. Epi-fluorescence and two-photon fluorescence microscopy images of $\mathrm{H} \mathrm{c} 2$ rat cardiomyoblasts stained with an efficient twophoton absorbing fluorene fluorophore is demonstrated. Additionally, single-photon spectral characteristics of the amine-reactive fluorophore, as well as the two-photon absorption cross sections of its model adduct in solution, and spectral characterization of a bovine serum albumin (BSA) as a model bioconjugate are presented. ๑ 2005 Society of Photo-Optical Instrumentation Engineers. [DOI: 10.1117/1.2104528]
\end{abstract}

Keywords: two-photon fluorescence; reactive dyes; multiphoton bioimaging.

Paper 05031 SS received Feb. 4, 2005; accepted for publication Mar. 10, 2005; published online Oct. 17, 2005.

\section{Introduction}

Two-photon excitation fluorescence microscopy (TPM), first demonstrated by Denk et al. ${ }^{1}$ in 1990 , is based on the condition of a fluorophore to simultaneously absorb two lower energy photons in a single quantum event to induce an electronic excitation that is normally accomplished by a single higher energy photon. ${ }^{2}$ The advantages of TPM have been de-

Address all correspondence to Kevin D. Belfield, Chemistry and School of Optics and Photonics, University of Central Florida P.O. Box 162366, Orlando, FL 32816-2366. Fax: 407-823-2252. E-mail: kblfiel@mail.ucf.edu scribed in detail elsewhere, ${ }^{3-5}$ and are inherently characterized by the high spatial localization of this excitation event via the quadratic relationship between the excitation and fluorescence intensity. Practically, this means fluorescence occurs only at the focal volume, and as near-IR laser irradiation is used as the excitation source, deeper imaging into optically thick tissue, with spatially restricted photobleaching and phototoxicity of the imaging specimen are achieved. The tenets of twophoton absorption (2PA) enable investigations of complex

1083-3668/2005/10(5)/051402/8/\$22.00 @ 2005 SPIE 
biological problems and experiments on living samples not possible with other imaging techniques, and highlighted examples of its use in the biological research areas have been noted. $^{6-8}$

Two-photon and higher multiphoton microscopies, utilizing judicious choices of optical probes, have yielded sophisticated and unparalleled imaging methods and techniques relative to what is achievable from linear fluorescence imaging methods. In the case of laser-scanning two-photon excited fluorescence microscopy, selecting the optimal fluorophore is critical, and databases of the 2PA and emission spectra for commonly used fluorophores and bio indicators have been generated to facilitate the selection process. ${ }^{9-13}$ Many of these compounds are conventional UV-excitable fluorophores, exhibiting low 2PA cross sections $(\delta)$, of the order of $\sim 10 \mathrm{GM}$ units $*$ with a few exhibiting $\sim 100 \mathrm{GM}$ units. The $\delta$ parameter is an indicator of the 2PA efficiency, and only recently has research been reported on the design and development of very efficient 2PA dyes possessing between 100 and several thousand GM units. ${ }^{14-19}$ A more salient feature of a fluorophore for its use in TPM is its two-photon excited fluorescence action cross section $\delta \eta$, the product of the 2PA cross section and fluorescence quantum yield $\eta$. Usually expressed in GM units, the action cross sections of these dyes are typically lower than the $2 \mathrm{PA}$ cross section. Higher values of $\delta \eta$ enable detection of lower dye concentrations with reduced laser power required for imaging, resulting in improved signal collection due to suppressed autofluorescence and less phototoxic effects on the sample. Hence, synthetic efforts focused on preparing new nonlinear optical probes specifically engineered to exhibit higher $\delta \eta$ are expected to outperform standard fluorophores currently in use for TPM imaging.

Until recently, optimization of nonlinear optical probes for multiphoton imaging applications have focused mainly on hydrophobic organic compounds studied in organic solvents. ${ }^{14-19}$ More current efforts are directed toward developing and evaluating analogous compounds with greater compatibility or relevance to biological environments, such as increasing hydrophilicity $^{20,21}$ as well as specificity, for which some examples ${ }^{22-28}$ are important cellular ions such as $\mathrm{Ca}^{2+}$ and $\mathrm{Mg}^{+2}$, zinc, and $\mathrm{H}^{+}$. However, identification and availability of optimized 2PA fluorophores specifically tailored for direct labeling of biomolecules for two-photon induced fluorescence imaging studies are limited. ${ }^{29,30}$ Currently, aminereactive fluorescent probes exhibiting high $2 \mathrm{PA}$ cross sections and sufficient action cross sections, specifically used to covalently label biomolecules are rare and appear to be limited to dipyrrylmetheneboron difluoride dyes. ${ }^{31}$ Therefore, the necessity to incorporate efficient reactive 2PA fluorophores with high action cross sections for covalent attachment onto biomolecules within the fluorophore design strategy seems timely and fulfills an appropriate requirement that coincides with increasing usage of two-photon excitation fluorescence imaging methods and techniques in the life sciences.

Previous studies from our laboratory have reported on the design and development of fluorene-based organic dyes with very efficient $2 \mathrm{PA}$ and fluorescence emission properties. ${ }^{14,30}$ The fluorene ring is a $\pi$-conjugated system that enables facile

\footnotetext{
*The 2PA cross section $\delta$ is usually expressed in GM (Goppert-Mayer) units, where $1 \mathrm{GM}$ equals $1 \times 10^{-50} \mathrm{~cm}^{4} \mathrm{~s}_{\text {photon }}$ molecule $^{-1}$.
}

synthetic manipulation, yielding dyes with tailored spectral and solubilizing properties. Two-photon excited fluorescence microscopy images of a well-characterized ${ }^{14} 2 \mathrm{PA}$ fluorene dye (1, Fig. 1 in Sec. 3.1) staining fixed rat cardiomyoblasts was demonstrated and lends credence to our motivation toward developing fluorene-based reagents for multiphoton bioimaging applications. Efforts directed toward preparing, in particular, reactive fluorescent reagents have been initiated with the synthesis of an amine-reactive tag (3, Fig. 5 in Sec. 3.2) for labeling, e.g., lysine residues on proteins. A model probeadduct (4) exhibiting high fluorescence quantum yield (QY $=0.74$ ) was also prepared by reacting (2) with $n$-butylamine to test its reactivity as an amine-reactive fluorescent label and its spectroscopic and labeling properties have been determined. Finally, a model protein bioconjugate (5) was prepared with the reactive fluorophore (3) and bovine serum albumin (BSA). Initial demonstration of the fluorenyl tag 3, as an amine-reactive 2PA fluorophore, is part of our continuing program toward developing more hydrophilic fluorene derivatives with higher action cross sections.

\section{Experiments}

\subsection{Materials, Methods, and Instruments}

All solvents and reagents were used as obtained from commercial sources unless specified. ${ }^{1} \mathrm{H}$ nuclear magnetic resonance (NMR) spectra were recorded on a Varian Mercury-300 NMR (300-MHz) spectrometer using tetramethylsilane (TMS) as the internal standard. ${ }^{13} \mathrm{C}$ NMR spectra were recoded on the same spectrometer $(75 \mathrm{MHz})$ using the carbon signal of the deuterated solvent as the internal standard. Chemical shifts $(\delta)$ are reported in parts per million (ppm). Elemental analyses were performed by Atlantic Microlab, Inc. (Norcross, Georgia). Fourier-transformed IR (FT-IR) spectra were recorded on a Perkin-Elmer Spectrum One spectrometer. UV to visible spectra were recorded on an Agilent 8453 spectrophotometer using standard 1-cm-path-length cuvettes. Steady state and fluorescent lifetime measurements were performed on a PTI Quantamaster spectrofluorometer. Fluorescence QY calculations were determined using a relative measurement $^{33}$ (Rhodamine 6G in ethanol). Two-photon induced fluorescence excitation spectrum of the dye-adduct 4 was performed using the two-photon fluorescence (TPF) method as described in detail in Ref. 32. Bright field transmission and epi-fluorescence microscope images of $\mathrm{H} 9 \mathrm{c} 2$ cells, stained with a well-characterized 2PA dye 1, were collected on a Nikon Eclipse E600 upright microscope. Twophoton excited fluorescence microscopy images of the same $\mathrm{H} 9 \mathrm{c} 2$ cells were performed on a modified Olympus IX 70 inverted microscope and Fluoview laser scanning unit accommodating a 10-W Verdi pumping a Ti:sapphire crystal of a Mira 900 (Coherent, Ref. 19).

\subsection{Glutaraldehyde Fixation of $\mathrm{H9c} 2 \mathrm{Rat}$ Cardiomyocytes Stained with a 2PA Fluorophore 1}

$\mathrm{H} 9 \mathrm{c} 2$ rat cardiomyoblast cells [American type culture collection (ATCC) CRL-1446] were plated in a four-well Lab-Tek II chamber slide (Fisher Scientific) and kept in a humidified atmosphere of $5 \% \mathrm{CO}_{2}$ at $37^{\circ} \mathrm{C} 24 \mathrm{~h}$ prior to dye staining. The 


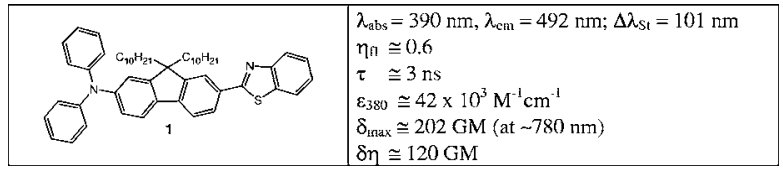

Fig. 1 Structure of a well-characterized 2PA fluorophore and its photophysical properties: $\lambda_{\mathrm{abs}}, \lambda_{\mathrm{em}}, \Delta \lambda_{\mathrm{St}}$ and $\varepsilon$ are linear absorption, steady state fluorescence emission, Stokes shift, and molar absorptivity, respectively; $\eta_{\mathrm{fl}}$, and $\tau$ are fluorescence quantum yield and lifetime, respectively; $\delta_{\max }$ and $\delta \eta$ are two-photon cross section and action cross section, respectively.

cells were in Dulbecco's modification of Eagle's medium (DMEM) (Mediatech, Inc.) supplemented with $10 \%$ fetal bovine serum (ATCC), 4-mM L-glutamine (Mediatech), and $100 \mu \mathrm{g} / \mathrm{mL}$ of penicillin-streptomycin (Mediatech) (complete medium). A glutaraldehyde fixation was followed as adapted from protocols presented by Bacallao and Stelzer. ${ }^{34}$ Briefly, cells were washed with phosphate buffer saline (PBS, $\mathrm{pH} 7.2$, Gibco) to remove growth medium. Cultures were fixed with $0.3 \%$ glutaraldehyde (Fisher Scientific) solution in PBS at room temperature, and their cell membranes permeabilized with a 1\% Triton-X100 (Sigma) in PBS solution. The detergent was removed with PBS washings, treated with freshly prepared solution of aqueous $\mathrm{NaBH}_{4}$ solution (1 $\mathrm{mg} / \mathrm{mL}$, Aldrich), followed by a brief rinse with $0.1 \%$ Triton-X100 in PBS (PBST). An aliquot of compound 1 $\left(10 \mu \mathrm{L}\right.$ of $\left.4.8 \times 10^{-4} \mathrm{M}\right)$ dissolved in anhydrous DMSO was delivered to the fixed cells in PBST solution. Details of the synthesis, linear and nonlinear characterization of compound 1 can be found in Refs. 14 and 32. One of the wells did not receive any dye as a control. Cells were washed with PBS (×4) followed by $\mathrm{ddH}_{2} \mathrm{O}$, and mounted in ProLong Gold (Molecular Probes) mounting medium, cover slipped and sealed.

\subsection{Synthesis of Amine-Reactive Fluorene Probe (3), [2-(9,9-didecyl-7-isothiocyanato- fluorenyl) benzothiazole]}

The synthesis of the reactive probe was prepared following a literature procedure. ${ }^{35}$ Briefly, compound 2 (0.48 g, 0.807 mmol), previously prepared, ${ }^{14}$ was dissolved in $\mathrm{CHCl}_{3}$ to which $\mathrm{CaCO}_{3}(0.21 \mathrm{~g}, 2.11 \mathrm{mmol})$ dissolved in $\mathrm{H}_{2} \mathrm{O}$ was added the mixture. Thiophosgene $(0.068 \mathrm{~mL}, 0.892 \mathrm{mmol})$ was added dropwise to the vigorously stirring mixture in an ice bath. After $\sim 10$ min the starting material was completely consumed as determined via TLC (silica, 2:1 hexanes $/ \mathrm{CH}_{2} \mathrm{Cl}_{2}$ ), and appeared to have gone to near quantitative conversion. After an additional $20 \mathrm{~min}, 10 \% \mathrm{HCl}_{\mathrm{aq}}$ was added until no gas generation was observed. The reaction mixture was poured into $\mathrm{H}_{2} \mathrm{O}$, extracted with $\mathrm{CH}_{2} \mathrm{Cl}_{2}$, dried over $\mathrm{MgSO}_{4}$, and on filtration and concentration, resulted in an orange oil. Purification was accomplished via flash chromatography (silica, 2:1 hexanes $/ \mathrm{CH}_{2} \mathrm{Cl}_{2}$ eluent). A pale yellow viscous oil was isolated (91\% yield). The FT-IR spectrum of isolated compound revealed the characteristic strong -NCS stretch at $2093 \mathrm{~cm}^{-1}$; no signal at $3600 \mathrm{~cm}^{-1}$ from the $-\mathrm{NH}_{2}$ group was observed. ${ }^{1} \mathrm{H}$ NMR $\left(300 \mathrm{MHz}, \mathrm{CDCl}_{3}\right)$ $\delta$ : $8.01(\mathrm{~s}, 1 \mathrm{H}, \mathrm{ArH}), 8.07$ (s, 1H, ArH), 8.04, $8.01(\mathrm{dd}, 1 \mathrm{H}$, ArH), 7.90 (d, 1H, ArH), 7.72 (d, 1H, ArH), 7.68 (d, 1H,
ArH), 7.49 (t, 1H, ArH), 7.38 (t, 1H, ArH), 7.23 (d, 1H, ArH), $7.20(\mathrm{~d}, 1 \mathrm{H}, \mathrm{ArH}) .{ }^{13} \mathrm{C} \mathrm{NMR}\left(75 \mathrm{MHz}, \mathrm{CDCl}_{3}\right) \delta: 166.0$, 154.0, 152.9, 151.5, 142.4, 139.1, 134.7, 134.5, 132.6, 130.1, 127.1, 126.2, 125.0, 124.7, 122.9, 121.4, 121.3, 120.9, 120.3, and 120.2. Calculated analyses for $\mathrm{C}_{41} \mathrm{H}_{52} \mathrm{~N}_{2} \mathrm{~S}_{2}$ (637.0): C, 77.31; H, 8.23; N 4.40. Found: C, 77.11; H, 8.45; N, 4.31.

\subsection{Synthesis of Dye Adduct (4), 1-(7- benzothiazol-9,9-didecyl-fluorenyl)- 3-butylthiourea}

A mixture of reactive reagent $3(0.85 \mathrm{~g}, 1.43 \mathrm{mmol})$ and $n$-butylamine $(1.0 \mathrm{~mL})$ was stirred at room temperature for 30 min. The excess butylamine was removed in vacuo, and the residue was purified by column chromatography using $\mathrm{CH}_{2} \mathrm{Cl}_{2} /$ hexane $[2 / 1(\mathrm{v} / \mathrm{v})]$ as eluent. Solvent removal and recrystallization from $n$-hexane afforded $0.67 \mathrm{~g}$ of white solid (66\% yield). Melting point (m.p.) 121 to $122^{\circ} \mathrm{C} ;{ }^{1} \mathrm{H}$ NMR $\left(250 \mathrm{MHz}, \quad \mathrm{CD}_{2} \mathrm{Cl}_{2}-\mathrm{D}_{2}\right) \quad \delta=7.99(\mathrm{~m}, 2 \mathrm{H}), 7.85 \quad(\mathrm{~d}$, $J=6.0 \mathrm{~Hz}, 1 \mathrm{H}), 7.72(\mathrm{~d}, J=6.5 \mathrm{~Hz}, 2 \mathrm{H}), 7.58(\mathrm{~s}, 1 \mathrm{H}), 7.42(\mathrm{t}$, $J=7.0 \mathrm{~Hz}, 2 \mathrm{H}), 7.31(\mathrm{t}, J=6.9 \mathrm{~Hz}, 2 \mathrm{H}), 7.13(\mathrm{~m}, 2 \mathrm{H}), 5.96$ $(\mathrm{s}, 1 \mathrm{H}), 3.53(\mathrm{~m}, 2 \mathrm{H}), 1.96(\mathrm{~m}, 4 \mathrm{H}), 1.46(\mathrm{~m}, 2 \mathrm{H}), 1.28(\mathrm{~m}$, $2 \mathrm{H}), 1.01(\mathrm{~m}, 28 \mathrm{H}), 0.85(\mathrm{t}, J=3.9 \mathrm{~Hz}, 3 \mathrm{H}), 0.73(\mathrm{t}$, $J=3.8 \mathrm{~Hz}, 6 \mathrm{H}), 0.56(\mathrm{~m}, 4 \mathrm{H})$. Calculated analyses for $\mathrm{C}_{45} \mathrm{H}_{63} \mathrm{~N}_{3} \mathrm{~S}_{2}$ (710.13): C, 76.11; H, 8.94; N, 5.92. Found: C, 76.28; H, 9.19; N, 5.90.

\subsection{Preparation and Characterization of the BSA- Fluorene Model Bioconjugate (5)}

Bovine serum albumin (Sigma, Fraction V, 99\%) was used as received for conjugation. The bioconjugation reaction was adapted as presented in Ref. 36. Briefly, a stock solution of BSA $(1 \mathrm{mg} / \mathrm{mL})$ in freshly prepared $\mathrm{NaHCO}_{2}(0.1 \mathrm{M}, \mathrm{pH} 9)$ solution was used. A stock solution of reactive tag (3) dissolved in anhydrous DMSO $\left(5.23 \times 10^{-3} \mathrm{M}\right)$ was freshly prepared and aliquots were slowly added dropwise into a gently stirring BSA solution ( $1 \mathrm{~mL}$ of stock). The concentration of the probe solution was varied such that a $1: 10$ and a $1: 5 \mathrm{~mol}$ ratio of protein to probe were prepared to establish a degree of labeling (DOL) for the probe. The reaction was covered from light and allowed to stir at room temperature for 1 to $2 \mathrm{~h}$, after which the mixture was passed through a Sephadex G-25 fine column (12 cm length, Fluka) equilibrated in and eluted with PBS (pH 7.2; Gibco). Fractions containing the bioconjugate were identified spectrophotmetrically by monitoring both the protein fraction at $280 \mathrm{~nm}$ and the dye at $360 \mathrm{~nm}$. The BSA protein concentration was approximated in the BSA-fluorene bioconjugate via a BSA calibration curve using the BeerLambert law. The molar absorptivity $\left(\varepsilon_{278}\right)$ of BSA in PBS (pH 7.2) was determined to be $39.4 \times 10^{3} \mathrm{Lmol}^{-1} \mathrm{~cm}^{-1}$ and corresponds well to the literature value ${ }^{37}$ of $\varepsilon_{278}=44$ $\times 10^{3} \mathrm{Lmol}^{-1} \mathrm{~cm}^{-1}$ (in $0.1 \mathrm{M}$ Tris-Cl, $\mathrm{pH} 8.2$ ). Calculation of the DOL was approximated from the product information page provided by Molecular Probes on amine-reactive probes and from Ref. 36. 

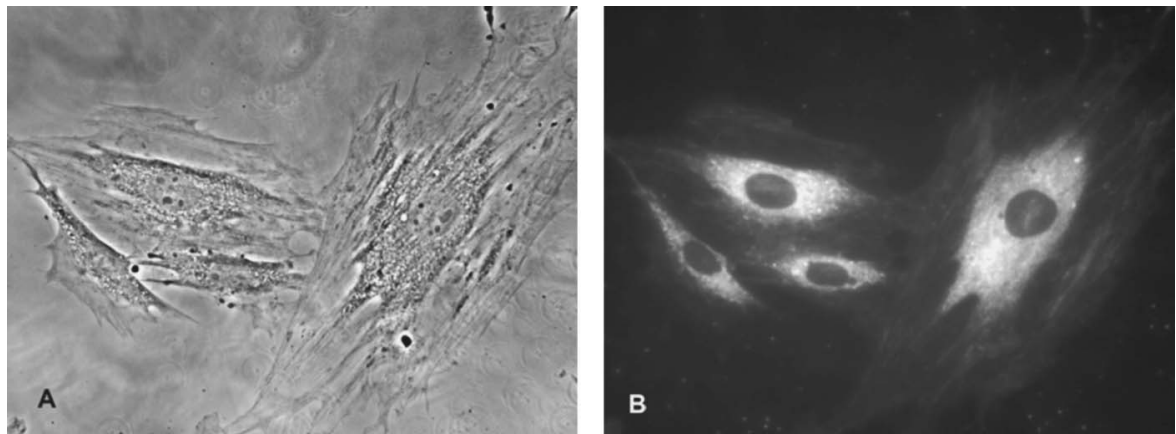

Fig. 2 (A) Bright field transmission and (B) epi-fluorescent microscopy images of H9c2 cells stained with a $2 \mathrm{PA}$ dye $\mathbf{1}$.

\section{Results and Discussion}

\subsection{Epi-Fluorescence and Two-Photon Excited Fluorescence Microscopy Images of H9c2 Cells Stained with a Two-Photon Absorbing Dye 1}

Compound $\mathbf{1}$ is a well-characterized fluorophore that exhibits relatively high $2 \mathrm{PA}$ cross sections in the excitation range of a pulsed Ti:sapphire laser output. Figure 1 shows the structure of compound 1 along with pertinent photophysical data characterized in acetone. Note that this compound was studied in a range of solvents of varying polarity, from hexanes to acetonitrile and acetone, and exhibits solvatochromic effects that influence its photophysical properties. Details of solvent effects on both its linear and nonlinear optical properties are presented in Ref. 32. Hence, the properties presented are indications of typical values to be expected from the highly photostable derivative. ${ }^{14}$ Note that additional fluorene derivatives with much higher cross sections, and hence, action cross sections, have been prepared, ${ }^{19}$ and choice of fluorene $\mathbf{1}$ was selected as a proof-of-principle demonstration that fluorene derivatives can be used in microscopy imaging of biological samples.

The utility of fluorene $\mathbf{1}$, and of additional fluorene-based derivatives, as efficient 2PA biological fluorophores was demonstrated by staining fixed $\mathrm{H} 9 \mathrm{c} 2$ rat cardiomyoblast cells.
Bright field transmission and epi-fluorescence microscope images [DAPI filter set, 40×, numerical aperture (NA) 0.75] of the stained cells are shown in Fig. 2. Furthermore, fluorene 1 did not undergo noticeable photobleaching during continuous exposure to the UV excitation light. No fluorescence was observed in the controls without any fluorophore (image not shown). Additionally, fluorescence was observed predominantly from the cytoplasmic region of the cells, with the nucleus clearly outlined, indicating potentially preferential staining of this fluorophore for cytoplasmic components.

TPM images of the same fluorene 1-stained cells were collected on a modified Olympus IX-70 inverted microscope and Fluoview laser scanning confocal unit with a Ti:sapphire laser output from 740 to $830 \mathrm{~nm}$ (125 fs FWHM, $76 \mathrm{MHz}$ repetition rate, $\sim 25 \mathrm{~mW}, 40 \times, \mathrm{NA} 0.85)$. The control cells that did not receive any fluorophore showed modest autofluorescence on $800 \mathrm{~nm}$ fs excitation, as shown in Fig. 3(C), while the fluorophore-stained cells [Fig. 3(D)] revealed higher contrast and greater signal under the same excitation and power exposure as the control. Two-photon induced fluorescence was observed predominantly from the cytoplasmic region, consistent with the images collected from epi-fluorescence images.

A direct quadratic dependency of fluorescence intensity on excitation power to verify a $2 \mathrm{PA}$ process was difficult to de-
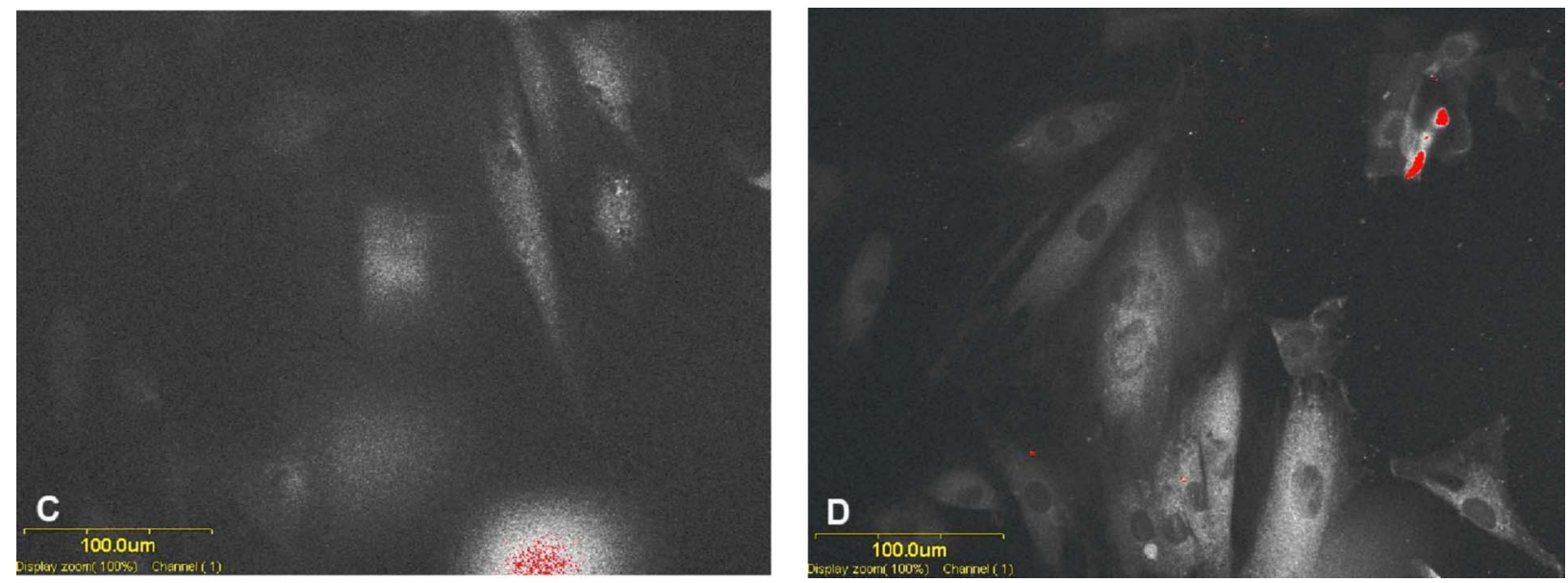

Fig. 3 TPM images of (C) blank containing no fluorophore and exhibiting some autofluorescence and (D) cells stained with fluorene $\mathbf{1}$ upon 800 $\mathrm{nm}$ fs excitation. Red spots demark signal saturation. 

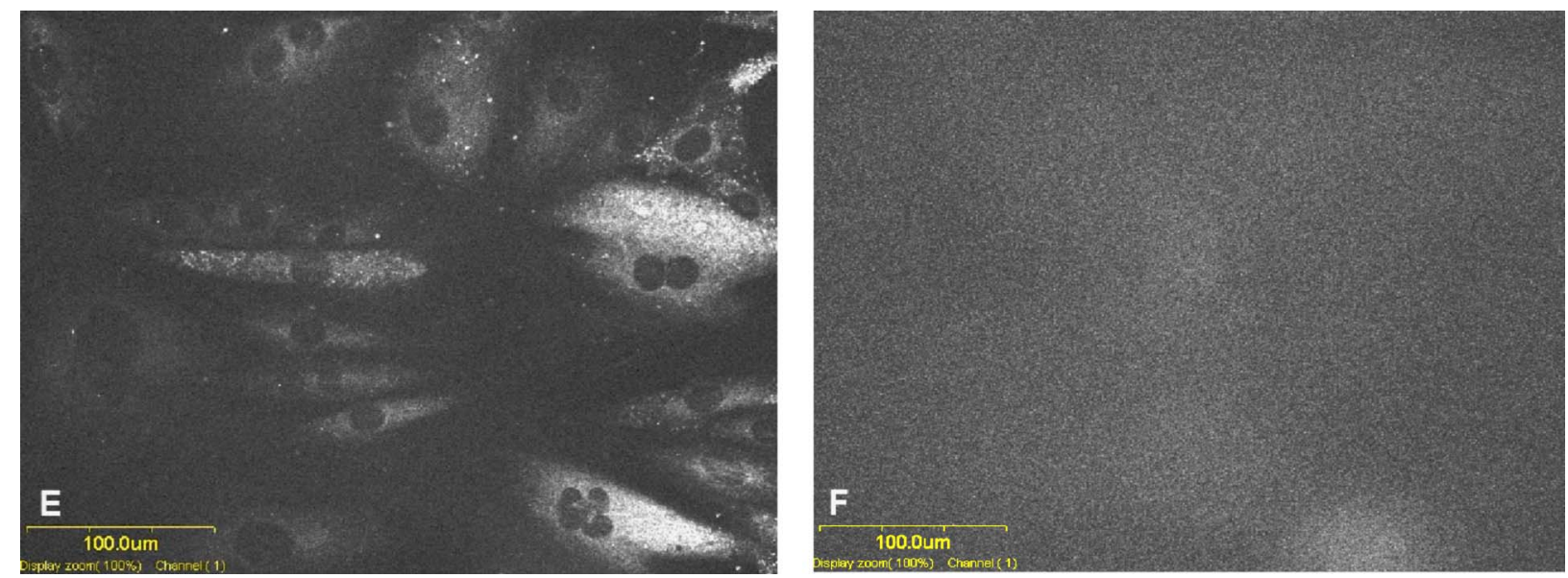

Fig. 4 TPM images of $\mathrm{H} 9 \mathrm{c} 2$ cells stained with fluorene 1 under (E) mode-locked and (F) non mode-locked Ti:sapphire irradiation conditions.

termine in the highly scattering sample. Hence, assertion of multiphoton excited fluorescence was verified by imaging the same sample area and image plane using the same average power under mode-locked (ML) and non-mode-locked (cw) conditions. A fluorescent image under ML conditions [Fig. $4(E)$ ] was clearly generated, while no image was obtained under $\mathrm{cw}$ conditions [Fig. 4(F)], and while higher order processes such as three-photon absorption may be involved, spectroscopic data suggest a two-photon process in the excitation range used (740 to $830 \mathrm{~nm}$ ) would be dominant for compound 1. Hence, two-photon excited fluorescence images of $\mathrm{H} 9 \mathrm{c} 2$ cells stained with fluorene $\mathbf{1}$ was demonstrated, providing strong motivation for the development of fluorene-based reactive reagents and probes for multiphoton bioimaging applications.

\subsection{Characterization of a Model Adduct (4) Prepared with an Amine-Reactive Fluorenyl Tag (3)}

Details of the synthesis and characterization of the fluorenyl derivative (2) was previously reported. ${ }^{14}$ Compound (3) was prepared as an amine-reactive fluorescent tag (Fig. 5), and contains the isothiocyanate functionality for covalent bond formation with primary amine groups present on protein molecules. A model dye-adduct (4) was also prepared by reacting (3) with $n$-butylamine to test its reactivity as an aminereactive fluorescent label. Preparation of the model adduct allowed for facile single- and two-photon spectroscopic characterizations that more closely resembles the bioconjugate than that of the reactive fluorophore alone.

The normalized UV to visible absorption and steady state fluorescence emission spectra of the free reactive tag (3) and the dye adduct (4) in DMSO are shown in Fig. 6. The free reactive fluorophore exhibits two absorption maxima at 357 and $375 \mathrm{~nm}$, along with two emission maxima at 384 and 404 nm. The dye adduct instead exhibits a single absorption maximum at $363 \mathrm{~nm}$ with an emission maximum at $403 \mathrm{~nm}$, and is well resolved from that of its absorption spectrum, with minimal spectral overlap. The fluorescence quantum yield of the reactive reagent in DMSO was 0.02, virtually nonfluorescent, while that of the dye adduct in DMSO increased significantly to 0.74 , indicating the fluorescence of the reactive tag is restored upon conjugation to a biomolecule.
The 2PA cross section for the dye adduct in DMSO was obtained using the two-photon induced fluorescence (2PF) method under femtosecond, near-IR irradiation conditions. In the $2 \mathrm{PF}$ method a strong, tunable pump beam excites the chromophore via 2PA, and the subsequent induced fluorescence is monitored as a function of the excitation wavelength. The $2 \mathrm{PF}$ results obtained for the fluorophore under investigation are calibrated against well-known reference standards. Furthermore, the quadratic dependence of $2 \mathrm{PF}$ on the pump irradiance is verified for multiple excitation wavelengths. A more detailed explanation of the experimental details can be found in Ref. 32 .

The linear absorption and fluorescence emission spectra of the model adduct (line and dashed profiles, respectively) and the two-photon induced fluorescence excitation spectrum measured at wavelengths twice that of the linear absorption (data points) are displayed in Fig. 7. The 2PF measurements of the model adduct were performed in DMSO (1.6 $\times 10^{-3} \mathrm{M}$ ), and exhibited a $2 \mathrm{PA}$ cross section of $\sim 25 \mathrm{GM}$ units at the linear absorption maximum of $370 \mathrm{~nm}$. With its fluorescence quantum yield of $\sim 0.74$, the action cross section for the model adduct is $\sim 19$ GM units. This is higher than most commonly used amine-reactive dyes. More importantly, additional hydrophilic fluorenyl derivatives, analogous in structure to compound $\mathbf{1}$, are being developed and are expected to exhibit higher action cross sections.

Interestingly, while the linear absorption spectrum for the compound does not display any significant absorption at the shorter wavelengths, the value of the 2PA cross section increases, possibly accessing higher excited-state transitions of the fluorophore. To ensure the dye adduct is undergoing twophoton absorption, a log-log plot of the femtosecond pump power to that of the integrated fluorescence was constructed. As we can see from Fig. 8, the slopes from the measurements (inset of graph) confirm the quadratic dependence of fluorescence obtained from a two-photon absorption process.

\subsection{Characterization of a Model Bioconjugate (5) Prepared with an Amine-Reactive Fluorenyl Tag (3)}

The amine-reactive fluorenyl reagent (3) was used to label BSA protein, a model biomolecule. The use of BSA, an inex- 

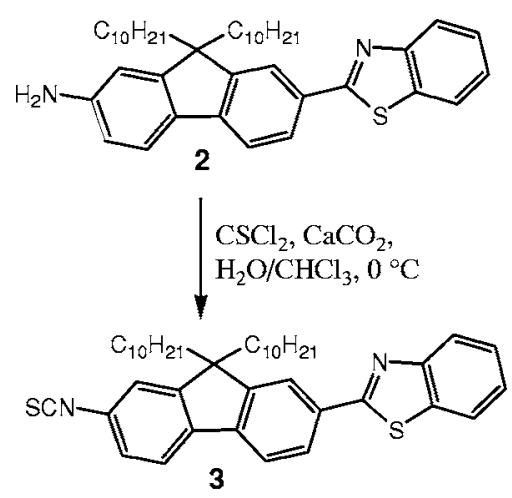

Reactive fluorophore

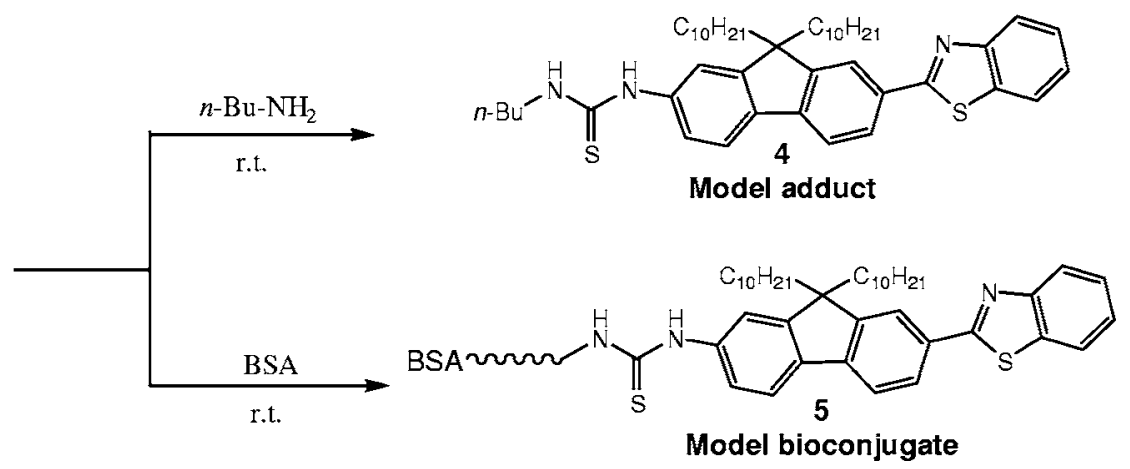

Model bioconjugate

Fig. 5 Preparation of the model adduct (4) and bioconjugate (5) with the amine-reactive fluorenyl reagent (3).

pensive protein that has been extensively characterized, is ideal for establishing optimal conditions to obtain a model bioconjugate, facilitating subsequent spectroscopic characterization. The isothiocyanate functionality reacts with aliphatic amine groups, including the $N$-terminus of proteins and the $\varepsilon$-amino groups of lysines $(\mathrm{pKa} \approx 10.5)$. A typical protocol for conjugation was followed in an amine-free buffer under slightly basic $\mathrm{pH}(\mathrm{pH}=9.0)$ conditions. The conjugate was identified spectrophotometrically and its steady state fluorescence emission spectra subsequently obtained. Two different molar ratios of the reactive dye to protein under different reaction times were performed to assess the reactivity of the dye for its DOL (Table 1). The DOL was estimated using standard equations obtained from Ref. 24. The DOL is a key parameter to establish as overlabeling of a fluorescent tag may interfere with the biological activity of a particular protein. Hence, a DOL value of $\sim 2.2$ to 3.4 was obtained with the amine-reactive tag, a typical range for amine-reactive probes.

The normalized absorption and steady state fluorescence emission spectra of the BSA-dye conjugate (5) in PBS buffer $(\mathrm{pH}$ 7.2) are shown in Fig. 9. For reference, the absorption

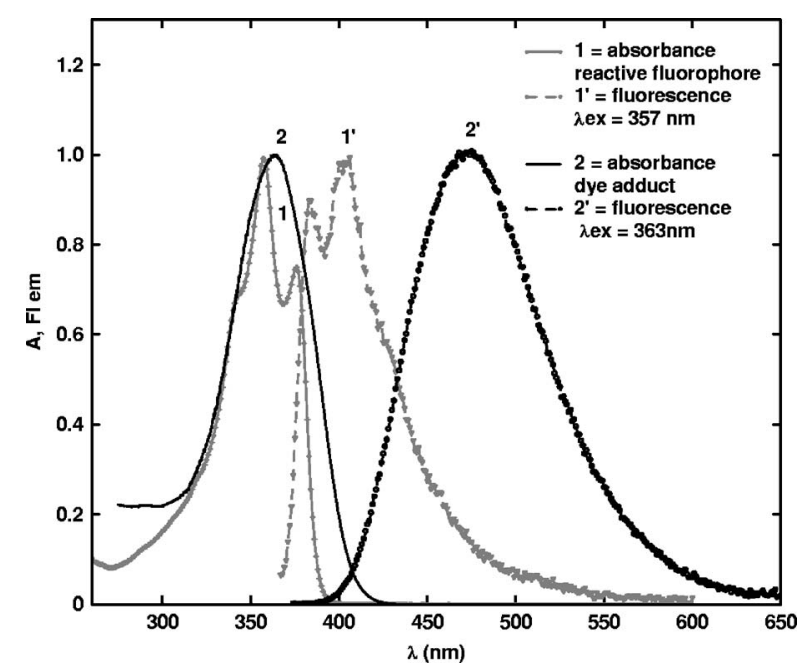

Fig. 6 Normalized UV to visible absorbance (1 and 2) and fluorescence emission (1' and 2'; excitation line indicated) spectra of the amine-reactive tag (3) and the dye adduct (4) in DMSO. spectrum of the free BSA protein in PBS solution is also shown. The conjugate displays absorption peaks corresponding to that of the BSA protein in the shorter wavelength range $\left(\lambda_{\max }=280 \mathrm{~nm}\right)$, as well as that of the fluorescent tag in the longer absorption range $\left(\lambda_{\text {maxima }}=360\right.$ and $\left.380 \mathrm{~nm}\right)$. The fluorescence emission of the bioconjugate is broad and exhibits an appreciable Stokes shift. A bathochromic shift in the fluorescence emission was observed in the BSA-dye conjugate, relative to that of the free reactive fluorophore. Similar to the broadening observed in the absorption profile, the fluorescence emission of the model conjugate was also broader than that of the free fluorophore. The observed Stokes shift in the free dye was about $45 \mathrm{~nm}$, while that of the BSA-dye conjugate was much greater (Stokes shift $=73 \mathrm{~nm}$ on $\lambda_{\mathrm{ex}}=360 \mathrm{~nm}$, and $53 \mathrm{~nm}$ on $\lambda_{\mathrm{ex}}=380 \mathrm{~nm}$ ). The fluorescence emission profile of the BSA-dye conjugate on excitation at $\lambda_{\mathrm{ex}}=360 \mathrm{~nm}$ and $\lambda_{\mathrm{ex}}=380 \mathrm{~nm}$ yielded similar fluorescence intensities. The

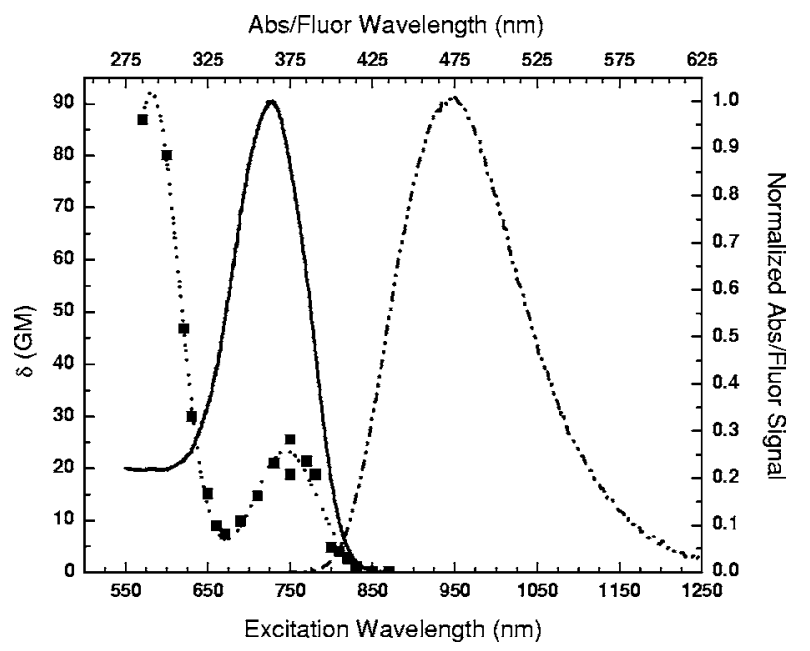

Fig. 7 Linear and nonlinear spectra of dye adduct in DMSO. The solid line is the normalized one-photon absorption spectrum; the dashed line is the normalized one-photon fluorescence spectrum. The twophoton induced fluorescence excitation spectrum is represented by filled symbols and the dotted line is a two-peaked Gaussian fitting function. The $y$ axis (left) denotes 2PA cross sections in GM units (1 $\times 10^{-50} \mathrm{~cm}^{4} \mathrm{~s}_{\text {photon }}{ }^{-1}$ molecule ${ }^{-1}$ ) and the $x$ axis (bottom) represents the two-photon excitation wavelength. 


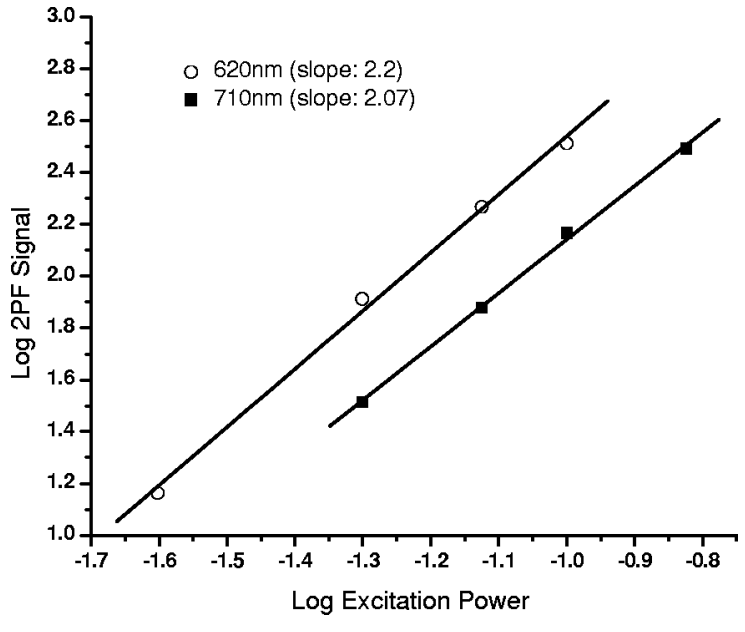

Fig. 8 Log-log plot of two-photon induced fluorescence signal versus excitation power at two different excitation wavelengths extracted from the data shown in Fig. 7. The solid lines are linear fitting functions whose slopes are indicated in the inset of the graph. The slopes show a quadratic dependence indicative of a two-photon induced process.

spectral profile of the model conjugate indicates the electronic property of the fluorenyl tag is perturbed upon binding and may additionally be affected by the proximity of the protein.

\section{Conclusion}

Development of fluorene-based reactive probes and tags for multiphoton bioimaging applications arises out of our systematic studies on the molecular structure to nonlinear optical property relationships for a wide range of fluorenyl derivatives. These derivatives exhibit desirable spectral properties, such as high photostability, high fluorescence quantum yields, high two-photon absorption cross sections, and therefore, action cross sections, over the tunability range of commercial Ti:sapphire lasers typically utilized in multiphoton imaging

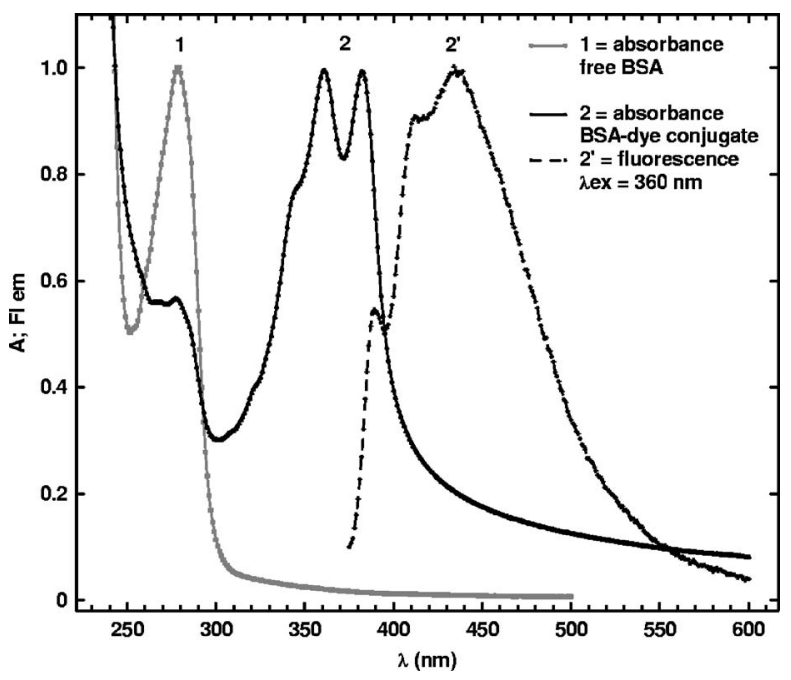

Fig. 9 Normalized absorption spectra of the free BSA protein and BSA-dye conjugate (1 and $\mathbf{2}$ ) and steady state fluorescence emission spectrum of the BSA-dye conjugate $\left(\mathbf{2}^{\prime}\right)$.
Table 1 Variable DOL obtained on altering the molar ratios of the reactive tag to BSA protein.

\begin{tabular}{ccccc}
\hline BSA & $\begin{array}{c}\text { Reactive } \\
\text { Fluorophore }\end{array}$ & $\begin{array}{c}\text { Dye: Protein } \\
\text { mol Ratio }\end{array}$ & $\begin{array}{c}\text { Reaction } \\
\text { Time }\end{array}$ & $\begin{array}{c}\text { DOL } \\
\text { mol protein) }\end{array}$ \\
\hline $\begin{array}{c}1.53 \times 10^{-8} \\
\mathrm{~mol}\end{array}$ & $1.53 \times 10^{-7} \mathrm{~mol}$ & $10: 1$ & $1 \mathrm{~h}$ & 3.4 \\
$\begin{array}{c}1.53 \times 10^{-8} \\
\mathrm{~mol}\end{array}$ & $7.7 \times 10^{-8} \mathrm{~mol}$ & $5: 1$ & $1 \mathrm{~h}$ & 2.4 \\
$\begin{array}{c}1.53 \times 10^{-8} \\
\mathrm{~mol}\end{array}$ & $7.7 \times 10^{-8} \mathrm{~mol}$ & $5: 1$ & $2 \mathrm{~h}$ & 2.2 \\
\hline
\end{tabular}

methods and techniques. Such properties make these fluorenyl derivatives compelling candidates for multiphoton bioimaging applications, and in particular, as probes or tags for direct covalent linkage onto biomolecules.

Demonstration of TPM images of H9c2 cells stained with a well-characterized 2PA fluorophore lends credence to our efforts to further refine fluorene-based derivatives for bioimaging applications. An amine-reactive fluorenyl tag was prepared and shown to effectively label primary amines as evidenced by preparing the model adduct. The model adduct allows for improved spectroscopic characterization. Furthermore, preparation of the model BSA-dye conjugate and its spectroscopic details validate the use of the fluorenylbase reactive tag (3) to form bioconjugates with protein biomolecules.

\section{Acknowledgments}

The National Science Foundation (ECS-0217932, DMR9975773), the National Research Council (COBASE), the Research Corporation, and the donors of The Petroleum Research Fund of the American Chemical Society and the Florida Hospital Gala Endowed Program for Oncologic Research Award are gratefully acknowledged for support of this work.

\section{References}

1. W. Denk, J. H. Strickler, and W. W. Webb, "Two-photon laser scanning fluorescence microscopy,” Science 249, 73-76 (1990).

2. M. Goppert-Mayer, "Uber elementarakte mit zwei quantensprungen," Ann. Phys. 9, 273-294 (1931).

3. J. R. Lakowicz, in Topics in Fluorescence Spectroscopy Vol. 5: NonLinear and Two-Photon-Induced Fluorescence, Plenum Press, New York (1997).

4. W. Denk, D. W. Piston, and W. W. Webb, "Two-photon molecular excitation in laser scanning microscopy," Chap. 28 in Handbook of Biological Confocal Microscopy, J. B. Pawley, Ed., pp. 445-458, Plenum Press, New York (1995).

5. A. Periasamy and P. T. So, Eds., Multiphoton Microscopy in the Biomedical Sciences III, SPIE Press, Bellingham, WA (2003).

6. R. M. Williams, W. R. Zipfel, and W. W. Webb, "Multiphoton microscopy in biological research," Curr. Opin. Chem. Biol. 5, 603-608 (2001).

7. K. Konig, "Multiphoton microscopy in life sciences," J. Microsc. 200, 83-104 (2000).

8. D. W. Piston, "Imaging living cells and tissues by two-photon excitation microscopy," Trends Cell Biol. 9, 66-69 (1999).

9. F. Bestvater, E. Spiess, G. Stobrawa, M. Hacker, T. Feurer, T. Porwol, U. Berchner-Pfannschmidt, C. Wotzlaw, and H. Acker, "Twophoton fluorescence absorption and emission spectra of dyes relevant 
for cell imaging," J. Microsc. 208, 108-115 (2002).

10. T. R. Neu, U. Kuhlicke, and J. R. Lawrence, "Assessment of fluorochromes for two-photon laser scanning microscopy of biofilms," Appl. Environ. Microbiol. 68, 901-909 (2002).

11. M. A. Albota, C. Xu, and W. W. Webb, "Two-photon fluorescence excitation cross sections of biomolecular probes from 690 to 960 ," Appl. Opt. 37, 7352-7356 (1998).

12. C. Xu, W. Zipfel, J. B. Shear, R. Williams, and W. W. Webb, "Multiphoton fluorescence excitation: new spectral windows for biological nonlinear microscopy," Proc. Natl. Acad. Sci. U.S.A. 93, 10763 10768 (1996).

13. C. Xu, and W. W. Webb, "Measurement of two-photon excitation cross sections of molecular fluorophores with data from 690 to 1050 nm," J. Opt. Soc. Am. B 13, 481-491 (1996).

14. K. D. Belfield, A. R. Morales, B.-S. Kang, J. M. Hales, D. J. Hagan, E. W. Van Stryland, V. M. Chapela, and J. Percino, "Synthesis, characterization and optical properties of two-photon absorbing fluorene derivatives," Chem. Mater. 16, 4634-4641 (2004); K. D. Belfield, A. R. Morales, J. M. Hales, D. J. Hagan, E. W. Van Stryland, V. M. Chapela, and J. Percino, "Linear and two-photon photophysical properties of a series of symmetrical diphenylaminofluorenes," Chem. Mater. 16, 2267-2273 (2004); K. D. Belfield, M. V. Bondar, O. V. Przhonska, and K. J. Schafer, "Photostability of a series of twophoton absorbing fluorene derivatives," J. Photochem. Photobiol., A 162, 489-496 (2004); K. D. Belfield, M. V. Bondar, O. V. Przhonska, and K. J. Schafer, "Photochemical properties of (7-benzothiazol-2-yl9,9-didecylfluoren-2-yl)diphenylamine under one- and two-photon excitation," J. Photochem. Photobiol., A, 162 569-574 (2004); K. D. Belfield, M. V. Bondar, O. V. Przhonska, and K. J. Schafer, "Steadystate spectroscopic and fluorescence lifetime measurements of new two-photon absorbing fluorene derivatives," J. Fluoresc. 12, 449-454 (2002); K. D. Belfield, M. V. Bondar, O. V. Przhonska, K. J. Schafer, and W. Mourad, "Spectral properties of several fluorene derivatives with potential as two-photon fluorescent dyes," J. Lumin. 97, 141146 (2002); K. D. Belfield, K. J. Schafer, W. Mourad, and B. A. Reinhardt, "Synthesis of new two-photon absorbing fluorene derivatives via Cu-mediated Ullmann condensation," J. Org. Chem. 65, 4475-4481 (2000); K. D. Belfield, D. J. Hagan, E. W. Van Stryland, K. J. Schafer, and R. A. Negres, "New two-photon absorbing fluorene derivatives: synthesis and nonlinear optical characterization," $\mathrm{Org}$. Lett. 1, 1575-1578 (1999); K. D. Belfield and K. J. Schafer, "A new photosensitive polymeric material for WORM optical data storage using multichannel two-photon fluorescence readout," Chem. Mater. 14, 3656-3662 (2002).

15. O. Mongin, L. Porres, L. Moreaux, J. Mertz, and M. BlanchardDesce, "Synthesis and photophysical properties of new conjugated fluorophores designed for two-photon-excited fluorescence," Org. Lett. 4, 719-722 (2002).

16. A. Abbotto, L. Beverina, R. Bozio, A. Facchetti, C. Ferrante, G. A. Panani, D. Pedron, and R. Signorini, "Novel heterocycle-based twophoton absorbing dyes," Org. Lett. 4, 1495-1498 (2002).

17. M. Rumi, J. E. Ehrlich, A. A. Heikal, J. W. Perry, S. Barlow, Z. Hu, D. McCord-Maughon, T. C. Parker, H. Rockel, S. Thayumanavan, S. R. Marder, D. Beljonne, and J.-L. Bredas, "Structure-property relationships for two-photon absorbing chromophores: Bis-donor diphenylpolyene and Bis(styryl)benzene derivatives," J. Am. Chem. Soc. 122, 9500-9510 (2000); M. Albota, D. Beljonne, J.-L. Bredas, J. E. Ehrlich, J.-Y. Fu, A. A. Heikal, S. E. Hess, T. Kogej, M. D. Levin, S. R. Marder, D. McCord-Maughon, J. W. Perry, H. Rockel, M. Rumi, G. Subramaniam, W. W. Webb, X-L. Wu, and C. Xu, "Design of organic molecules with large two-photon absorption cross sections," Science 281, 1653-1656 (1998).

18. B. A. Reinhardt, L. L Brott, S. J. Clarson, A. G. Dillard, J. C. Bhatt, R. Kannan, L. Yuan, G. S. He, and P. N. Prasad, "Highly active two-photon dyes: design, synthesis, and characterization toward application," Chem. Mater. 10, 1863-1874 (1998).

19. P. C. Cheng, S. J. Pan, K.-S. Kim, W. S. Liou, and M. S. Park, "Highly efficient upconverters for multiphoton fluorescence microscopy," J. Microsc. 189, 199-212 (1998).

20. H. Y. Woo, J. W. Hong, B. Liu, A. Mikhailovsky, D. Korystov, and G. C. Bazan, "Water-soluble [2.2]paracyclophane chromophores with large two-photon action cross sections," J. Am. Chem. Soc. 123, 820821 (2005)
21. A. Margineanu, J. Hofkens, M. Cotlet, S. Habuchi, A. Stefan, J. Qu, C. Kohl, K. Mullen, J. Vercammen, Y. Engelborghs, T. Gensch, and F. C. De Schryver, "Photophysics of a water-soluble rylene dye: comparison with other fluorescent molecules for biological applications," J. Phys. Chem. B 108, 12242-12251 (2004).

22. S. J. K. Pond, O. Tsutsumi, M. Rumi, O. Kwon, E. Zojer, J.-L. Bredas, S. R. Marder, and J. W. Perry, "Metal-ion sensing fluorophores with large two-photon absorption cross sections: aza-crown ether substituted donor-acceptor-donor distyrlbenzenes," J. Am. Chem. Soc. 136, 9291-9306 (2004).

23. H. M. Kim, M-Y. Jeong, H. C. Ahn, S.-J. Jeon, and B. R. Cho, "Two-photon sensor for metal ions derived from azacrown ether," J. Org. Chem. 69, 5749-5751 (2004).

24. A. Miyawaki, O. Griesbeck, R. Heim, and R. Y. Tsien, "Dynamic and quantitative $\mathrm{Ca}^{2+}$ measurements using improved chameleons," Proc. Natl. Acad. Sci. U.S.A., 96, 2135-2140 (1999); S. R. Adams, V. LevRam, R. Y. Tsien, and Y. Roger, "A new caged $\mathrm{Ca}^{2+}$, azid-1, is far more photosensitive than nitrobenzyl-based chelators," Chem. Biol. 4, 867-878 (1997).

25. M. Taki, J. L. Wolford, and T. V. O'Halloran, "Emission ratiometric imaging of intracellular zinc: design of a benzoxazole fluorescent sensor and its application in two-photon microscopy," J. Am. Chem. Soc. 126, 712-713 (2004).

26. C. J. Chang, E. M. Nolan, J. Jaworski, K.-I. Okamoto, Y. Hayashi, M. Sheng, and S. J. Lippard, "ZP8, a neuronal zinc sensor with improved dynamic range; imaging zinc in hippocampal slices with twophoton microscopy," Inorg. Chem. 43, 6774-6779 (2004).

27. S. Charier, O. Ruel, J.-B. Baudin, D. Alcor, J.-F. Alleman, A. Meglio, and L. Jullien, "An efficient fluorescent probe for ratiometric $\mathrm{pH}$ measurements in aqueous solutions," Angew. Chem., Int. Ed. 43, 4785-4788 (2004).

28. M. H. V. Werts, S. Gmouh, O. Mongin, H. Pons, and M. BlanchardDesce, "Strong Modulation of two-photon excited fluorescence of quadripolar dyes by (de)protonation," J. Am. Chem. Soc. 126, 16294 16295 (2004).

29. G. Piszczek, B. P. Maliwal, I. Gryczynski, J. Dattelbaum, and J. R. Lakowicz, "Multiphoton ligand-enhanced excitation of lanthanides," J. Fluoresc. 11, 101-107 (2001).

30. T. Y. Ohulchanskyy, H. E. Pudavar, S. M. Yarmoluk, V. M. Yashchuk, E. J. Bergey, and P. N. Prasad, "A monomethine cyanine dye cyan 40 for two-photon-excited fluorescence detection of nucleic acids and their visualization in live cells," Photochem. Photobiol. 77, 138-145 (2003).

31. N. J. Meltola, R. Wahlroos, and A. E. Soini, "Hydrophilic labeling reagents of dipyrrylmethene-BF2 dyes for two-photon excited fluorometry: syntheses and photophysical characterization," J. Fluoresc. 14, 635-647 (2004); N. J. Meltola, A. E. Soini, and P. E. Hanninen, "Syntheses of novel dipyrrylmethene-BF2 dyes and their performance as labels in two-photon excited fluoroimmunoassay," J. Fluoresc. 14, 129-138 (2004).

32. J. M. Hales, D. J. Hagan, E. W. Van Stryland, K. J. Schafer, A. M. Morales, K. D. Belfield, P. Pacher, O. Kwon, and J. L. Bredas, "Resonant enhancement of two-photon absorption in substituted fluorene molecules," J. Chem. Phys. 121, 3152-3160 (2004); J. M. Hales, K. J. Schafer, A. M. Morales, K. D. Belfield, D. J. Hagan, and E. W. Van Stryland, "Nonlinear optical spectroscopic characterization of a series of fluorene derivatives," Proc. SPIE 5211, 21-30, (2003).

33. J. Lackowicz, in Principles of Fluorescence Spectroscopy, Plenum Press, New York (1999).

34. R. Bacallao and E. H. K. Stelzer, "Preservation of biological specimens for observation in a confocal fluorescence microscope and operational principles of confocal fluorescence microscopy," Methods Cell Biol. 31, 437-452 (1989).

35. J. Garin, E. Melendez, F. L. Merchan, P. Merino, J. Orduna, and T. Tejere, "Synthesis of unsymmetrical diheteroarylbenzenes: benzazole and quinazoline derivatives," J. Heterocycl. Chem. 28, 359-363 (1991).

36. R. P. Haugland, in Methods in Molecular Biology: Monoclonal Antibody Protocols, Vol. 45, Chap. 22, W. C. Davis, Ed., pp. 205-214, Humana Press, Totowa, N. J. (1995).

37. T. A. Bewley, "A novel procedure for determining protein concentrations from absorption spectra of enzyme digests," Anal. Biochem. 123, 55-65 (1982). 